\title{
Recombinant Plasmids Capable of Replication in B. subtilis and E. coli
}

\author{
J. Kreft, K. Bernhard, and W. Goebel
}

Institut für Genetik und Mikrobiologie, Universität Würzburg, Röntgenring 11, D-8700 Würzburg, Federal Republic of Germany

Summary. The plasmid $p B C 16$ (4.25 kbases), originally isolated from Bacillus cereus, determines tetracycline resistance and can be transformed into competent cells of $B$. subtilis. A miniplasmid of $p B C 16$ $(p B C 16-1), 2,7 \mathrm{~kb}$ ) which has lost an Eco RI fragment of $p B C 16$ retains the replication functions and the tetracycline resistance. This plasmid which carries only one EcoRI site has been joined in vitro to $p B S 1$, a cryptic plasmid previously isolated from $B$. subtilis and shown to carry also a single EcoRI site (Bernhard et al., 1978). The recombinant plasmid is unstable and dissociates into the plasmid $p B S 161(8.2 \mathrm{~kb})$ and the smaller plasmid $p B S 162(2.1 \mathrm{~kb})$. Plasmid $p B S 161$ retains the tetracycline resistance. It possesses a single EcoRI site and 6 HindIII sites. The largest HindIII fragment of $p B S 161$ carries the tetracycline resistance gene and the replication function. After circularization in vitro of this fragment a new plasmid, $p B S 161-1$ is generated, which can be used as a HindIII and EcoRI cloning vector in Bacillus subtilis.

Hybrid plasmids consisting of the $E$. coli plasmids $p B R 322, p W L 7$ or $p A C 184$ and different HindIII fragments of $p B S 161$ were constructed in vitro. Hybrids containing together with the $E$. coli plasmid the largest HindIII fragment of $p B S 161$ can replicate in $E$. coli and B. subtilis. In E. coli only the replicon of the $E$. coli plasmid part is functioning whereas in $B$. subtilis replication of the hybrid plasmid is under the control of the Bacillus replicon. The tetracycline resistance of the $B$. subtilis plasmid is expressed in $E$. coli, but several antibiotic resistances of the $E$. coli plasmids (ampicillin, kanamycin and chloramphenicol) are not expressed in B. subtilis. The hybrid plasmids seem to be more unstable in $B$. subtilis than in E. coli.

\section{Introduction}

Recently, we have reported on the isolation and characterization of a large number of plasmids from $B$. subtilis and B. cereus (Bernhard et al., 1978). Among those a rather small plasmid, $p B C 16$, originally isolated from a tetracycline resistant strain of $B$. cereus could be transformed into B. subtilis, where it is stably maintained rendering the transformants resistant to tetracycline. The molecular properties of this plasmid (size, copy number, sites for restriction enzymes, genetic marker) made it appear a suitable vector for gene cloning in B. subtilis. We have therefore started experiments to insert fragments from other $B$. subtilis and $E$. coli DNA molecules into this plasmid and to analyze the resultant recombinant DNAs.

Other vector plasmids suitable for the application of this new genetic method in B. subtilis have been recently reported (S. Ehrlich, 1977). These plasmids derive from Staphylococcus aureus.

Like $p B C 16$ they seem to be suitable vectors for gene cloning in B. subtilis (S. Ehrlich, personal communication; P. Lovett, personal communication). We have made the experience, however, that they seem to be considerably more unstable in the new host than $p B C 16$. This report describes experiments, which demonstrate that $p B C 16$ and some of its in vitro constructed derivatives can be used for cloning of homologous and heterologous DNA in Bacillus subtilis.

\section{Materials and Methods}

Bacterial Strains. E. coli $5 \mathrm{~K}, \mathrm{r}^{-}, \mathrm{m}^{+}$was obtained from S. Glover. JC $1569 \mathrm{recA}^{-}, t h y^{+}, \mathrm{arg}^{-}, h i \mathrm{~s}^{-}, \mathrm{met}^{-}, l e u^{-}, S \mathrm{~m}^{\mathrm{R}}$ harbouring plasmid pAC184 was a gift from Cohen and Chang. E. coli DP9, polA ${ }^{-}, \mathrm{r}^{-}, \mathrm{m}^{-}$was provided by $\mathrm{Ph}$. Kourilsky. B. subtilis $168 \mathrm{tr} \mathrm{p}^{-}$ (DSM 402) was from the Deutsche Sammlung von Mikroorganismen, B. subtilis BR151-CM1 $t r p^{-}, l y s^{-}, m e t^{-}, s p o^{-}$was kindly provided by $P$. Lovett. The other strains used here, were described before (Bernhard et al., 1978; Kollek et al., 1978).

Source of Reagents. All reagents if not otherwise stated were from Merck, Germany. The antibiotics used were a gift from Bayer, Germany. Sodium dodecyl sulfate (SDS), ethidium bromide, polyethylenglycol type 6000 , lysozyme, pancreatic R Nase and pronase P from $S$. griseus were obtained from Serva, Germany. 
Enzymes. The restriction enzyme EcoRI was provided by H. Mayer (Braunschweig), HindIII and T4 DNA ligase was purchased from Bio Labs (USA).

Growth of Strains, Cell Lysis and Purification of Plasmid DNA were performed as previously described (Mayer et al., 1977; Bernhard et al., 1978)

Cleavage of DNA and Electrophoresis in Agarose Gels. Digestion with EcoRI was carried out in $100 \mathrm{mM}$ Tris- $\mathrm{HCl} \mathrm{pH} 7.5,50 \mathrm{mM}$ $\mathrm{NaCl}, 5 \mathrm{mM} \mathrm{MgCl} 2$ at $37^{\circ} \mathrm{C}$ for $30 \mathrm{~min}$, with HindIII in $10 \mathrm{mM}$ Tris- $\mathrm{HCl} \mathrm{pH} \mathrm{7.5,25} \mathrm{mM} \mathrm{NaCl,} 10 \mathrm{mM} \mathrm{MgCl}_{2}$ at $37^{\circ} \mathrm{C}$ for $60 \mathrm{~min}$. The reactions were stopped by heating to $68^{\circ} \mathrm{C}$ for $8 \mathrm{~min}$ or by addition of $100 \mathrm{mM}$ EDTA. Electrophoresis was performed on $1 \%$ agarose slab gels in $36 \mathrm{mM}$ Tris- $\mathrm{HCl}, 30 \mathrm{mM} \mathrm{NaH} \mathrm{PO}_{4}$ $10 \mathrm{mM}$ EDTA, pH 7.5 (Meyers et al., 1975)

Construction of Hybrid Plasmids and Transformation. The in vitro construction of hybrid plasmids (Cohen et al., 1973) using T4 DNA ligase, transformation of E. coli and of B. subtilis have been described (Goebel and Bonewald, 1975; Cahn and Fox, 1968). Transformants of $E$. coli were first selected on nutrient broth (ENB) plates containing $100 \mu \mathrm{g} / \mathrm{ml}$ ampicillin (in the case of $p B R 322$ or $p W L 7$ hybrids) or $100 \mu \mathrm{g} / \mathrm{ml}$ chloramphenicol (for $p A C 184$ hybrids). Growing colonies were then tested for sensitivity to $5-50 \mu \mathrm{g} / \mathrm{ml}$ tetracycline (pBR322 and pAC184 hybrids), to $100 \mu \mathrm{g} / \mathrm{ml}$ kanamycin (for $p W L 7$ hybrids). In addition $p W L 7$ hybrids $\left(\mathrm{Km}^{\mathrm{s}}\right)$ were tested for sensitivity against $5-50 \mu \mathrm{g} / \mathrm{ml}$ tetracycline.

Determination of the Intracellular $\beta$-Lactamase Activity. The enzyme was assayed with hydroxylamine/ammonium ferric sulphate (Dale and Smith, 1971). 1 unit corresponds to the amount of enzyme which catalyses the hydrolysis of one $\mu$ mole ampicillin/ $\min$ at $30^{\circ} \mathrm{C}$ in $0.025 \mathrm{M}$ Tris- $\mathrm{HCl}, \mathrm{pH} 7.4$

\section{Results}

In vitro Construction of Recombinant Plasmids from B. subtilis Plasmid pBS1 and B. cereus Plasmid $p B C 16$

The tetracycline resistance plasmid $p B C 16(4.2 \mathrm{~kb})$ was previously isolated from $B$. cereus and transformed into B. subtilis 168 (Bernhard et al., 1978). Restriction endonuclease EcoRI cleaves this plasmid into two fragments of $2.7 \mathrm{~kb}$ and $1.5 \mathrm{~kb}$. The cryptic plasmid $p B S 1(7.8 \mathrm{~kb})$ of $B$. subtilis carries a single $E c o$ RI site. To construct in vitro recombinant plasmids carrying both replicons, $p B C 16$ was either completely or partially digested by EcoRI and ligated, using T4 DNA ligase, with EcoRI cleaved $p B S 1$. The ligated mixture was transformed into B. subtilis 168 made competent as described (Cahn and Fox, 1968). Tetracycline resistant $\left(\mathrm{Tc}^{\mathrm{R}}\right)$ colonies were obtained with a frequency of about $10^{-6}$. Covalently-closed circular (CCC) DNAs where isolated from several of the obtained clones. None of them represented the expected hybrid plasmid consisting of both replicons. Instead, the CCC-DNAs isolated from several $\mathrm{Tc}^{\mathrm{R}}$ clones could be identified as:

a) pBC16-1: Some of tetracycline resistant cells harbour one small plasmid of $2.7 \mathrm{~kb}$, which carries a single EcoRI site. This plasmid, which can be also obtained by transforming $B$. subtilis with $p B C 16$, completely digested by $E c o$ RI and then ligated in vitro, represents the circularized large EcoRI fragment of $p B C 16$ (Fig. 1). This mini $p B C 16$ plasmid, named $p B C 16-1$, thus carries the tetracycline resistance gene and the replication functions of $p B C 16$.

b) pBC16-2: Other $\mathrm{Tc}^{\mathrm{R}}$-transformants harbour two plasmids of $5.8 \mathrm{~kb}$ and $4.2 \mathrm{~kb}$. The smaller one is identical to $p B C 16$. Transformation of the isolated larger plasmid yields tetracycline resistant colonies which harbour again both plasmids. Cleavage of the mixture of both plasmids by EcoRI (Fig. 1) yields only the two fragments which are also obtained after cleavage of $p B C 16$ DNA alone. Since the size difference between $p B C 16$ and the larger plasmid, $p B C 16-2$, is $1.5 \mathrm{~kb}$ and hence identical to the small EcoRI fragment of $p B C 16$, we conclude that plasmid $p B C 16-2$ carries a second small EcoRI fragment of $p B C 16$ inserted into $p B C 16$. This plasmid is, however, unstable and eliminates at a rather high rate one of the two identical fragments.

c) pBS161 and pBS162: A large number of the tetracycline resistant colonies harbour two plasmids of $8.2 \mathrm{~kb}(p B S 161)$ and $2.1 \mathrm{~kb}(p B S 162)$ (Fig. 1). Plasmid $p B S 161$ alone but not $p B S 162$ yields also tetracycline resistant colonies when transformed into competent $B$. subtilis cells. This plasmid being larger in size than $p B S 1$ but smaller than the expected sum of $p B S 1$ and $p B C 16$ or one of its two EcoRI fragments, carries only one EcoRI site (Fig. 1) but 6 HindIII sites. Comparison of the HindIII patterns of $p B S 1$ and $p B S 161$ reveals that fragments $\mathrm{B}, \mathrm{C}, \mathrm{E}, \mathrm{F}$ and $\mathrm{G}$ are identical with $p B S 1$ (Fig. 2 and Fig. 4). Fragment $\mathrm{D}$ of $p B S 1$ is lost, whereas fragment $A^{\prime}$ has obviously incorporated additional DNA from $p B C 16$ including the gene determining tetracycline resistance. The smaller plasmid pBS162 being present in the original clones carries also one EcoRI and one HindIII site. Since it represents a replicating DNA element it must possess one of the replicon functions of the two parent plasmids $p B C 16$ or $p B S 1$. The sum of the sizes of $p B S 161$ and $p B S 162$ is $10.3 \mathrm{~kb}$ which is roughly identical to the sum of $p B S 1$ and the larger EcoRI fragment of $p B C 16(10.5 \mathrm{~kb})$. It appears therefore rather likely that a hybrid plasmid consisting of the large EcoRI 


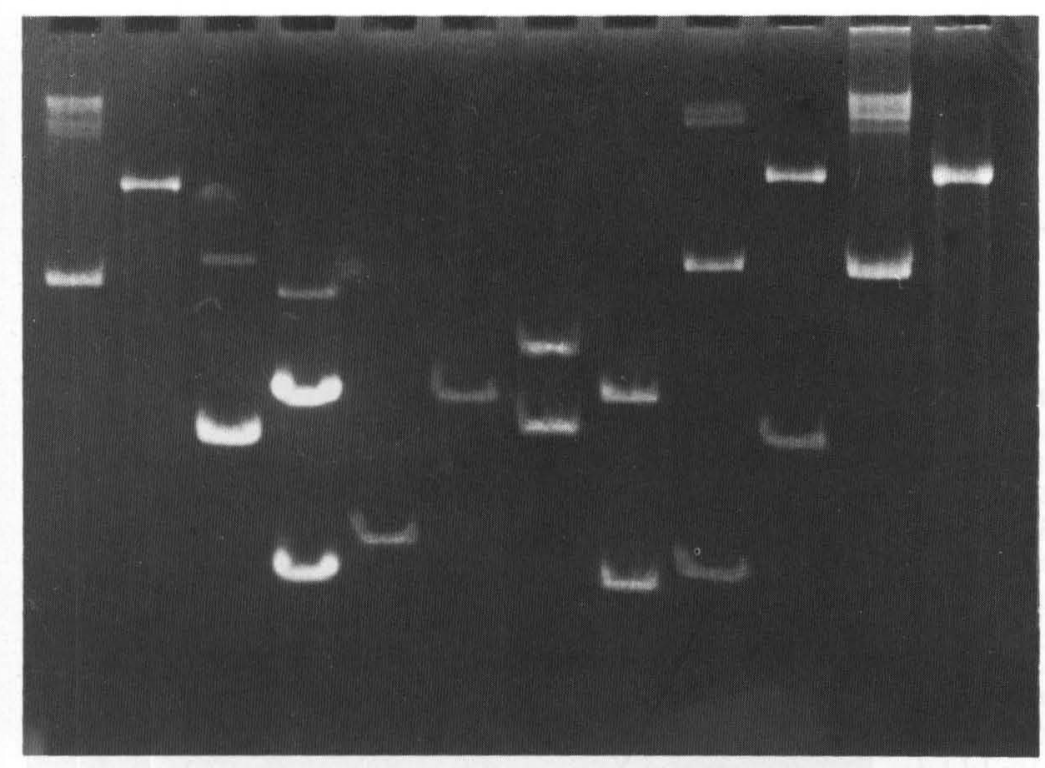

\section{A}

Fig. 1A-M. Plasmids obtained after transformation of B. subtilis 168 with in vitro recombinant DNA consisting of $p B C 16$ and $p B S 1$. Plasmid $p B C 16$ and $p B S 1$ were cleaved by EcoRI and ligated with T4 DNA ligase as described (Cohen et al., 1973). Transformation into B. subtilis was performed by the procedure of Cahn and Fox, 1968. $T c^{\mathrm{R}}$-colonies were picked, their covalently-closed circular DNAs isolated and analysed on an $1 \%$ agarose gel $(2 \mathrm{~mA} / \mathrm{cm}, 17 \mathrm{~h})$. A $p B S 1$, B $p B S 1$ cleaved with EcoRI, C $p B C 16, \mathbf{D} p B C 16$ cleaved with EcoRI, E $p B C 16-1, \mathbf{F} p B C 16-1$ cleaved with EcoRI, G $p B C 16$ and $p B C 16-2, \mathbf{H} p B C 16$ and $p B C 16-2$ cleaved with $E c o$ RI, $\mathbf{J} p B S 161$ and $p B S 162, \mathbf{K} p B S 161$ and $p B S 162$ cleaved with $E c o$ RI, L $p B S 161, \mathbf{M} p B S 161$ cleaved with EcoRI

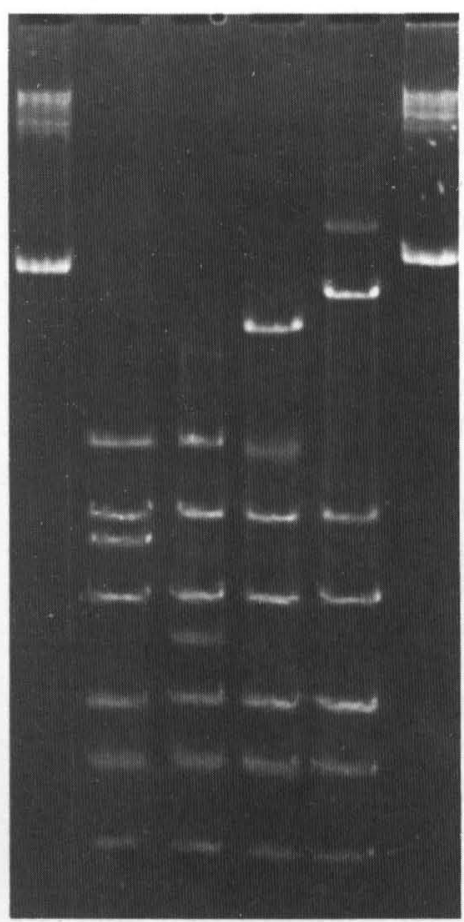

\section{A $\quad B \quad C \quad D \quad E$ F}

Fig. 2 A-F. Comparison of the HindIII and HindIII/EcoRI patterns of $p B S 1$ and $p B S 161$. Covalently closed DNA of $p B S 1$ and $p B S 161$ was cleaved with HindIII and HindIII + Eco RI, respectively. The fragments were separated by electrophoresis on an $1 \%$ agarose gel. A $p B S 1$ CCC-DNA, B $p B S 1$ cleaved with HindIII, C $p B S 1$ cleaved with HindIII and Eco RI. D pBS161 cleaved with HindIII and EcoRI, E $p B S 161$ cleaved with HindIII, F pBS161 CCC-DNA.
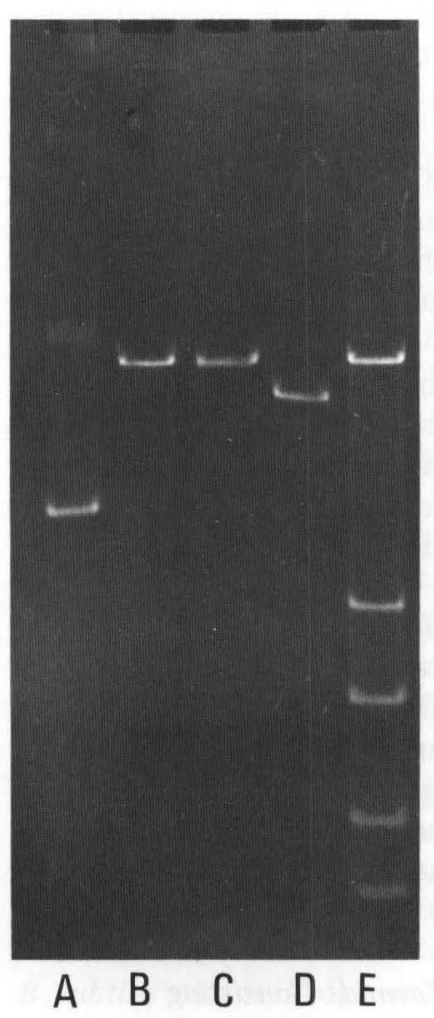

Fig. 3 A-E. Gel electrophoresis of plasmid $p B S 161-1$, obtained by cleaving of $p B S 161$ with HindIII and transformation of the religated DNA into $B$. subtilis 168. A Covalently closed pBS161-1 DNA, B $p B S 161-1$ DNA cieaved with Eco RI, C with HindIII, D with EcoRI and HindIII (the small fragment of 300 bp can not be seen on this gel). E $p B S 161$ cleaved with HindIII 


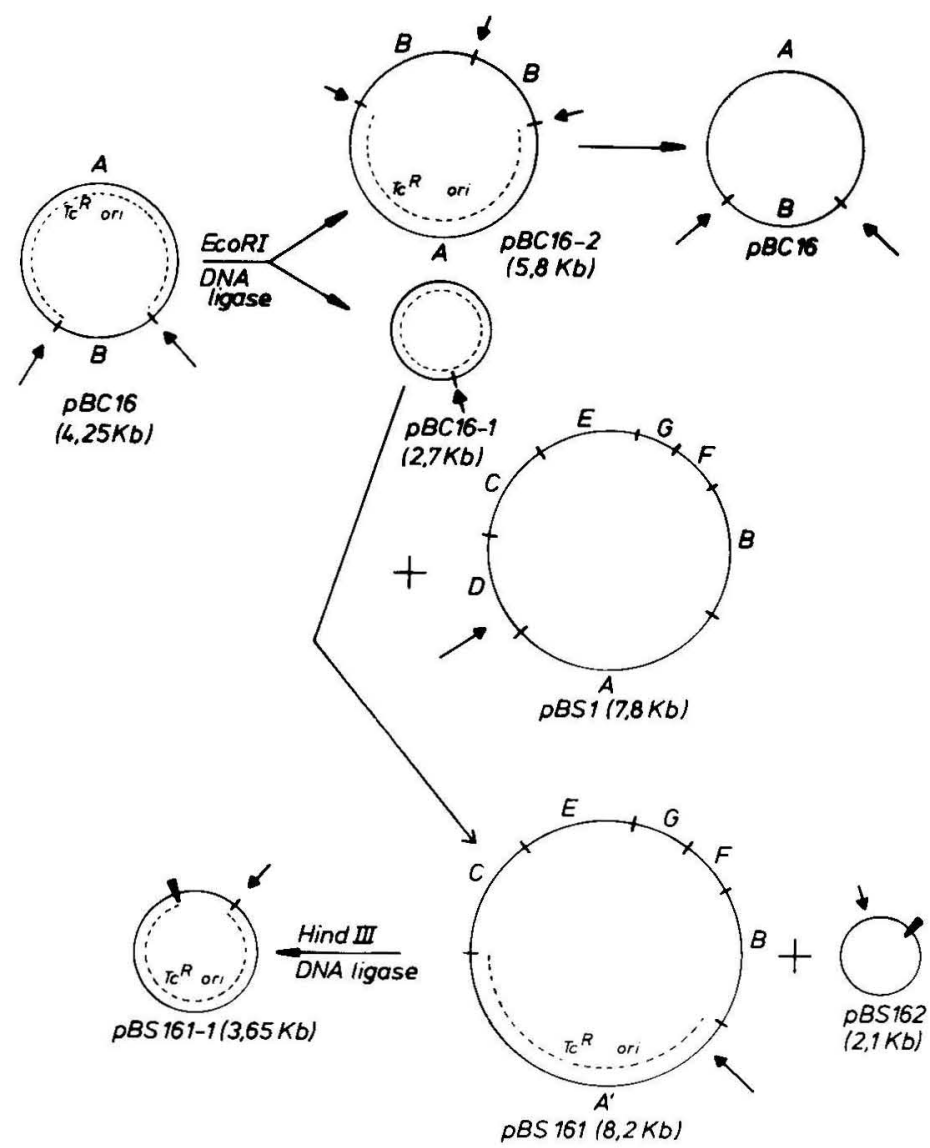

Fig. 4. Genealogy of the $B$. subtilis vector plasmids $p B C 16, p B C 16-1, p B S 161$ and $p B S 161-1$ fragment of $p B C 16$, which carries the tetracycline resistance and the replication functions of $p B C 16$, and $p B S 1$ was formed in vitro. However, after transformation in B. subtilis the recombinant plasmid which consists now of two replicons is unstable and dissociates nonreciprocally into $p B S 161$ and $p B S 162 . p B S 161$ was cleaved with HindIII and the fragments were recircularized in vitro with DNA ligase. After transformation in B. subtilis $\mathrm{Tc}^{\mathrm{R}}$-colonies are obtained, that carry a new plasmid $p B S 161-1$ which represents the circularized HindIII-A fragment of pBS161 (Fig. 3) which indicates that this fragment carries the tetracycline resistance determinant and the replication function of $p B S 161$. This fragment has retained in addition one EcoRI site. Figure 4 summarizes the formation of the various derivatives of $p B C 16$.

\section{Construction of Hybrid Plasmids Consisting of Hind III Fragments of pBS161}

and E. coli Plasmids $p B R 322, p W L 7$ or $p A C 184$

Plasmid $p B S 161$ was digested by restriction endonuclease HindIII and ligated, using T4 DNA ligase, with the E. coli plasmids $p B R 322$ (Boyer et al., 1977), $p W L 7$
(Kollek et al., 1978), or pAC184 (S. Cohen and A. Chang, unpublished), which were also linearized by $H$ indIII. These $E$. coli plasmids were used as vectors since insertion of a HindIII fragment into their single $H$ indIII sites inactivates the tetracycline resistance (in the case of $p B R 322$ and $p A C 184)$ or the kanamycin resistance (in the case of $p W L 7$ ), but leaves another antibiotic resistance determined by these plasmids intact which can then be used for selection of transformants $\left(\mathrm{Ap}^{\mathbf{R}}\right.$ for $p B R 322$ and $p W L 7$, and $C m^{\mathbf{R}}$ for $p A C 184)$. The in vitro ligated mixtures were transformed into $E$. coli $5 \mathrm{~K}\left(\mathrm{r}^{-}, \mathrm{m}^{+}\right)$and hybrid clones were selected by inactivation of the corresponding marker. When clones, obtained after transformation with ligated HindIII cleaved $p B R 322$ and HindIII fragments of $p B S 161$ were tested for inactivation of tetracycline resistance, two different types of clones were obtained: Clones which were completely sensitive to tetracycline and clones which still retained a low level of tetracycline resistance. Whereas strains carrying the original plasmid $p B R 322$ are resistant to $100 \mu \mathrm{g} \mathrm{ml}$ tetracycline, the upper limit of resistance of the latter clones is $15 \mu \mathrm{g} / \mathrm{ml}$.

Both, tetracycline sensitive and low-level tetracycline resistant colonies contained hybrid plasmids, as 


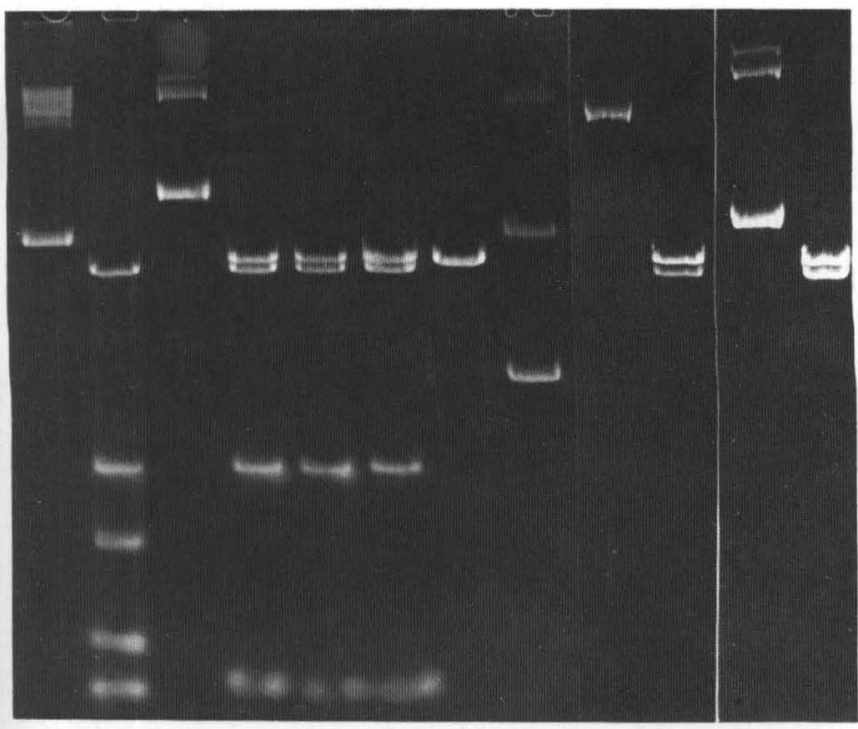

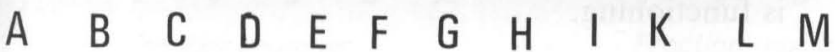

Fig. 5A-M. Agarose gel electrophoresis of HindIII-cleaved hybrid plasmids consisting of E. coli plasmid $p B R 322$ and HindIII fragments of $p B S 161$. Covalently closed hybrid DNA was isolated from the indicated strains and cleaved with HindIII. A pBS161-CCC-DNA, B pBS161 cleaved with HindIII, C CCC-pJK1 DNA from E. coli $5 \mathrm{~K}$, D cleaved with HindIII, E $p J K 1$ DNA from E. coli MM383 (polA12) cleaved with HindIII, F $p J K 1$ DNA from $B$. subtilis 168 cleaved with HindIII, G $p B R 322$ cleaved with HindIII. H CCC-pBR322, J CCC-pJK2 DNA from $E$. coli $5 \mathrm{~K}, \mathbf{K}$ cleaved with HindIII. L CCC-pJK3 DNA from $E$. coli $5 \mathrm{~K}$. M cleaved with HindIII
Table 1. Characterization of hybrid plasmids consisting of E. coli vectors pBR322 or pWL7 and various HindIII fragments of $B$. subtilis plasmid pBS161

\begin{tabular}{lclll}
\hline Plasmid & $\begin{array}{l}\text { Molecular } \\
\text { weight } \\
(\times 1000 \\
\text { b.p. })\end{array}$ & $\begin{array}{l}\text { E. coli } \\
\text { vector }\end{array}$ & $\begin{array}{l}\text { HindIII frag- } \\
\text { ments of } \\
\text { pBS161 inserted } \\
\text { into the } \\
\text { E. coli vector }\end{array}$ & $\begin{array}{l}\text { Transforma- } \\
\text { tion rate } \\
\text { in } \text { B. sub- } \\
\text { tilis } 168\end{array}$ \\
\hline JK1 & 9.8 & $p B R 322$ & A, B, E & $2.6 \times 10^{-5}$ \\
$p J K 2$ & $11.5^{\text {a }}$ & $p B R 322$ & $\mathrm{~A}$ & $1.4 \times 10^{-5}$ \\
$p J K 3$ & 7.6 & $p B R 322$ & $\mathrm{~A}$ & $5.3 \times 10^{-5}$ \\
$p J K 4$ & 5.6 & $p B R 322$ & $\mathrm{~B}$ & 0 \\
$p J K 101$ & 15.75 & $p W L 7$ & $\mathrm{~A}$ & $2.4 \times 10^{-5}$ \\
$p B R 322$ & 3.9 & - & - & 0 \\
$p W L 7$ & 12.1 & - & - & 0 \\
$p B C 16$ & 4.25 & - & - & $2.0 \times 10^{-5}$ \\
$p B C 16-1$ & 2.7 & - & - & $4.5 \times 10^{-5}$ \\
$p B S 161$ & 8.2 & - & - & $1.9 \times 10^{-5}$ \\
\hline
\end{tabular}

This plasmid contains two molecules of $p B R 322$ linked to one HindIII-A fragment

b Transformation rate is defined as the ratio of $\mathrm{Tc}^{\mathrm{R}}$ transformants per $10^{8}$ cells and $3 \mu \mathrm{g}$ of DNA used in the transformation assay

demonstrated by cleaving the isolated CCC-DNA with HindIII (Fig. 5). Most plasmids isolated from clones which retained the low tetracycline resistance had the largest HindIII fragment (HindIII-A) of $p B S 161$ incorporated into $p B R 322$ (Table 1). Lowlevel tetracycline resistant colonies were also obtained when $p W L 7$ plasmid $\left(K m^{\mathrm{R}}, A p^{\mathrm{R}}\right)$ was used as vector for the cloning of the HindIII fragment of $p B S 1$. The $T c^{\mathrm{R}}$ colonies carried hybrid plasmids which had also HindIII fragment A incorporated into $p W L 7$. Since plasmid $p W L 7$ does not determine tetracycline resis- tance, this result indicates that the low tetracycline resistance is expressed by the cloned HindIII-A fragment of $p B S 161$. One clone, also resistant to low concentrations of tetracycline, contained a hybrid plasmid, $p J K 4$, which had fragment HindIII-B of $p B S 161$ incorporated into $p B R 322$ (Table 1). Since the HindIII site in $p B R 322$ inactivates the promotor of the $T c^{\mathrm{R}}$ gene, but not the structural gene it was assumed that the tetracycline resistance of $p J K 4$ may be caused by the replacement of the inactive own promotor by a B. subtilis promotor located on fragment HindIII-B. Plasmid $p J K 4$ was therefore cleaved by HindIII, religated with DNA ligase in vitro and transformed into $E$. coli $5 \mathrm{~K}$. Ampicillin resistant transformants were obtained, which were either $T c^{\mathrm{R}}$ or $T c^{\mathrm{S}}$. The $T c^{\mathrm{S}}$ transformants contained $p J K 4$ with HindIII-B inserted in the opposite direction as in the original $p J K 4$, whereas $T c^{\mathrm{R}}$ transformants contained either $p J K 4$ in the original orientation or $p B R 322$ only (Fig. 6).

Purified hybrid plasmids obtained in the former cloning experiments in E. coli were used to transform competent B. subtilis cells. Selection for transformed colonies was performed on tetracycline containing plates. $T c^{\mathrm{R}}$ transformants were obtained with all hybrid plasmids containing fragment HindIII-A from $p B S 161$. Tetracycline resistance of these transformed B. subtilis strains is high and comparable to the tetracycline resistance $(100 \mu \mathrm{g} / \mathrm{ml})$ of the parent plasmid $p B S 161$. CCC-DNA isolated from the B. subtilis clones is identical to the hybrid plasmid DNA isolated from $E$. coli and used for the transformation, i.e. the plasmid DNA in both hosts remains identical (Fig. 5). Similiar results were obtained with hybrid 

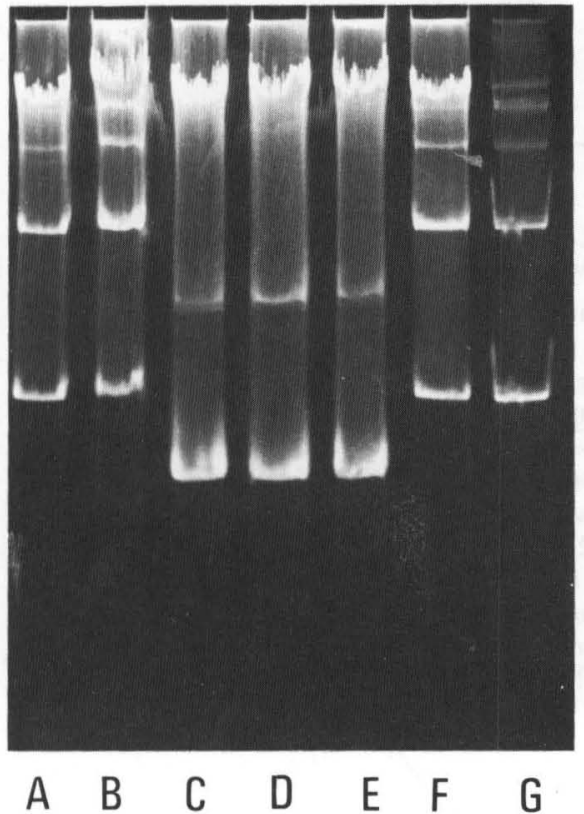

Fig. 6A-G. Recloning of $p J K 4$ hybrid DNA. Hybrid $p J K 4$ DNA from low-level $T c^{\mathrm{R}}$ colonies of $E$. coli $5 \mathrm{~K}$ was isolated. The DNA was cleaved with HindIII and religated with T4 DNA ligase. The DNA was transformed into $E$. coli $5 \mathrm{~K} . T c^{\mathrm{R}}$ and $T c^{\mathrm{S}}$-colonies were obtained. Cleared lysates of $T c^{\mathrm{R}}$ and $T c^{\mathrm{S}}$ colonies were prepared and analysed by agarose gel electrophoresis. A, B cleared lysates from $T c^{\mathrm{S}}$-clones containing $p J K 4$ DNA with HindIII-B fragment inserted into $p B R 322$ in the opposite orientation as in the original $p J K 4$ DNA. C-E cleared lysates from $T c^{\mathrm{R}}$-clones containing $p B R 322$ DNA only, $\mathbf{F}$ cleared lysate from $T c^{\mathrm{R}}$-clone containing the original $p J K 4$ DNA, G $p J K 4$ DNA as control

plasmids of $p W L 7$ having HindIII fragment A incorporated (data not shown).

Transformation of B. subtilis BR151-CM1 a nonsporulating derivative of B. subtilis 168 (kindly provided by $\mathrm{P}$. Lovett) with $p B C 16-1$ and the hybrid plasmid $p J K 101$ leads also to tetracycline resistant colonies. The transformation rate is comparable to that of $B$. subtilis 168 , indicating that this nonsporulating $B$. subtilis mutant can be also used as a host for recombinant DNA.

\section{Replication Control of Hybrid Plasmids}

The $E$. coli plasmids used as vectors for the described cloning experiments are ColE1 derivatives. Their replication is therefore dependent on high dosis of DNA polymerase I (Kingsbury and Helinski, 1970) and continues in the presence of chloramphenicol (Clewell, 1972). To test which replicon of the obtained hybrid plasmids capable of replication in both hosts is functional, the following experiments were performed: a) Transformation of $p J K 1-3$ (see Table 1) in $E$. coli DP9 polA ${ }^{-}, r^{-}, m^{-}$does not yield transformants. Transformants of MM383, polA12 (carrying a temperature sensitive DNA polymerase I) obtained with this plasmid are unable to grow at $43^{\circ} \mathrm{C}$ on tetracycline and/or ampicillin containing plates.

b) Addition of chloramphenicol to a culture of $E$. coli harbouring $p J K 1$ leads to an amplification of this plasmid. However, the copy number of the hybrid plasmid increases only $3-5$ fold after treatment with this antibiotic. Treatment of B. subtilis 168 harbouring $p J K 1$ with chloramphenicol leads to a complete stop of plasmid synthesis (Fig. 7). The experiment was performed with chloramphenicol concentrations between 5 and $150 \mu \mathrm{g} / \mathrm{ml}$. The results indicate that in $E$. coli the ColEl replicon but not the Bacillus subtilis replicon is active whereas in $B$. subtilis only the $B$. subtilis but not the ColE1 replicon is functioning.

\section{Differences in Gene Expression \\ of the Hybrid Plasmids in E. coli and B. subtilis}

As described in the preceeding section the gene determining resistance to tetracycline in B. subtilis is also expressed in E. coli, although the level of resistance in the new host is lower. Experiments to insert in vitro the EcoRI fragment of pML21 conferring resistance to kanamycin in E. coli (Hershfield et al., 1974) into EcoRI-cleaved plasmid $p B C 16$ of B. subtilis were performed. The ligated mixture which contained according to the analysis on an agarose gel at least $80 \%$ ligated DNA was used to transform B. subtilis. Although a large number of $\mathrm{Tc}^{\mathrm{R}}$-transformants were obtained none of them were resistant to kanamycin.

The hybrid plasmids $p J K 1-3$ and $p J K 101$ which determine in $E$. coli resistance to ampicillin and tetracycline, showed resistance to tetracycline only, after transformation into B. subtilis. The lack of expression of the ampicillin resistance gene of E. coli in B. subtilis is not caused by a modification of the hybrid DNA in $B$. subtilis, since these plasmids isolated from $B$. subtilis and retransformed into $E$. coli lead again to $A p^{\mathrm{R}}$ and $T c^{\mathrm{R}}$ colonies.

To test whether $\beta$-lactamase of $p J K 2$ is synthesized in B. subtilis but not excreted, B. subtilis harbouring $p J K 2$ was analysed for intracellular $\beta$-lactamase activity by the method of Dale and Smith, 1971. No $\beta$-lactamase could be detected (Table 2).

Similiar experiments were performed with hybrid plasmids consisting of $p B S 161-1$ (fragment HindIII-A of $p B S 1$ ) and the E. coli vector plasmid $p A C 184$ deter- 
of autonomous replication are located on an EcoRI fragment of $2.7 \mathrm{~kb}$, which upon circularization results in a new autonomously replicating plasmid $p B C 16-1$, which appears to be a suitable EcoRI vector for cloning of genes in B. subtilis.

Joining of this plasmid to another cryptic extrachromosomal element from B. subtilis, $p B S 1$, does not lead to a stable bifunctional replicon as expected. Instead, the recombinant DNA dissociates in all clones studied into two new autonomously replicating elements $p B S 161$ and $p B S 162$. The reason for this apparent instability of a recombinant DNA consisting of two functional replicons in B. subtilis is unknown. In $E$. coli such bifunctional replicons have been constructed (Cabello et al., 1976; Kollek et al., 1978; Mayer et al., 1977) and shown to be stable.

The tetracycline resistance remains, after dissociation, on the larger plasmid, $p B S 161$, which carries only one EcoRI site and can be also used as EcoRI vector for B. subtilis. The plasmid has in addition six HindIII sites from $p B S 1$. The largest HindIII fragment carries the tetracycline resistance and the genetic information required for autonomous replication. Upon circularization of this fragment an autonomously replicating plasmid $p B S 161-1$ is generated which represents a HindIII vector for B. subtilis.

Recombinant plasmids consisting of this HindIII fragment and an E. coli plasmid like $p B R 322, p W L 7$ or $p A C 184$ are capable of stable replication in $B$. subtilis and $E$. coli. The dependency of replication of these recombinant plasmids on polA in $E$. coli and their inability to replicate in $B$. subtilis in the presence of chloramphenicol indicate that only the homologous replicon is functioning in the corresponding host.

The investigation of the gene expression of the recombinant DNAs in $E$. coli and B. subtilis indicates a rather interesting difference between $E$. coli and $B$. subtilis. Whereas the tetracycline resistance of the $B$. subtilis plasmid can be expressed in $E$. coli-although at a lower level than in the natural host-several antibiotic resistances from $E$. coli (kanamycin-, ampicillin- and chloramphenicol resistance) are not expressed in $B$. subtilis. Trivial explanations for this lack in heterologous gene expression in $B$. subtilis could be ruled out: Modification of the recombinant plasmid in E. coli or B. subtilis does not occur. The orientation of insertion of the fragment is of no influence in any case. It could also be shown that no TEM- $\beta$-lactamase determined by the $E$. coli gene is synthesized inside the $B$. subtilis cell.

It remains to be seen whether this lack of heterologous gene expression is a general phenomenon in $B$. subtilis. Since gene expression in the opposite tion, i.e. B. subtilis genes in E. coli, is possible (Ehrlich et al., 1976; Mahler and Halvorson, 1977) and the expression of other heterologous genes from Grampositive and Gram-negative bacteria in E. coli has been repeatedly demonstrated (for a summary, see Vosberg, 1978), one may speculate that Gram-positive bacteria may have a more limited potential for expression of genetic information from Gram-negative than vice versa. There is also evidence that the heterologous DNA from the recombinant plasmids is more unstable in $B$. subtilis than in $E$. coli. The reason for this difference is also unknown.

It should be emphasized that not only the wildtype strain of $B$. subtilis, but also a non-sporulating mutant of it yields comparable transformation rates with the Bacillus subtilis vector plasmid alone and recombinant DNA constructed with it. This makes $B$. subtilis a rather safe host system for gene cloning.

While this manuscript was in preparation, we learned that similiar results concerning the lack of expression of E. coli genes in B. subtilis were obtained by S.D. Ehrlich (PNAS, in press) using plasmids from $S$. aureus as cloning vehicle.

Acknowledgements. We thank S.D. Ehrlich for sending us his manuscript prior to publication. S. Cohen is thanked for providing the plasmid pAC184, Ph. Kourilsky for the E. coli strain DP9 polA ${ }^{-}, \mathrm{r}^{-}, \mathrm{m}^{-}$and P. Lovett for B. subtilis BR151-CM1.

We are thankful to Miss M. Vogel and Miss B. Schelle for skillful technical assistance.

This work was supported by a grant from the Deutsche Forschungsgemeinschaft (SFB 105-A1)

\section{References}

Bernhard, K., Schrempf, H., Goebel, W.: Bacteriocin and antibiotic resistance in Bacillus cereus and Bacillus subtilis. J. Bact. 133, 897-903 (1978)

Boyer, H.W., Betlack, M., Bolivar, F., Rodriguez, R.L., Heyneker, H.L., Shine, J., Goodman, H.M.: Recombinant molecules: Impact on science and society (Beers, R.F. and Bassett, E.B., eds.) pp. 9-20. New York: Raven Press 1977

Cabello, F., Timmis, K., Cohen, S.N.: Replication control in a composite plasmid constructed by in vitro linkage of two distinct replicons. Nature (Lond.) 259, 285-290 (1976)

Cahn, F., Fox, M.: Fractionation of transformable bacteria from competent cultures of $B$. subtilis on renografin gradients. J. Bact. 95, 869-875 (1968)

Clewell, D.B.: Nature of ColEl plasmid replication in Escherichia coli in the presence of chloramphenicol. J. Bact. 110, 667-676 (1972)

Cohen, S.N., Chang, A.C.Y., Boyer, H.W., Helling, R.B.: Construction of biologically functional bacterial plasmids in vitro. Proc. nat. Acad. Sci. (Wash.) 70, 3240-3244 (1972)

Dale, J.W., Smith, J.T.: The purification and properties of the $\beta$-lactamase specified by the resistance factor R-1818 in $E$. coli and $P$. mirabilis. Biochem. J. 123, 493-500 (1971)

Ehrlich, S.D.: Replication and expression of plasmids from Staphylococcus aureus in Bacillus subtilis. Proc. nat. Acad. Sci. (Wash.) 74, 1680-1682 (1977) 
Ehrlich, S.D., Brusztyn-Pettegrew, H., Stroynowski, I., Lederberg, $\mathrm{J}$. : Expression of the thymidylate synthetase gene of the Bacillus subtilis bacteriophage Phi-3-T in Escherichia coli. Proc. nat. Acad. Sci. (Wash.) 73, 4145-4149 (1976)

Goebel, W., Bonewald, R.: Class of small multicopy plasmids originating from the mutant antibiotic resistance factor $\mathrm{R} 1 d r d$ 19B2. J. Bact. 123, 658-665 (1975)

Hershfield, V., Boyer, H.W., Yanofsky, C., Lovett, M., Helinski, D.R.: Plasmid ColEl as a molecular vehicle for cloning and amplification of DNA. Proc. nat. Acad. Sci. (Wash.) 71, 3455-3459 (1974)

Kingsbury, D., Helinski, D.R. : DNA polymerase as a requirement for the maintenance of the plasmid colicinogenic factor E1. Biochem. biophys. Res. Commun. 41, 1538-1544 (1970)

Kollek, R., Oertel, W., Goebel, W.: Isolation and characterization of the minimal fragment required for autonomous replication ("basic replicon") of a copy mutant ( $p K N 102)$ of the antibiotic resistance factor R1. Molec. gen. Genet. 162, 51-57 (1978)
Mahler, I., Halvorson, H.O.: Transformation of Escherichia coli and Bacillus subtilis with a hybrid plasmid molecule. J. Bact. 131, 374-377 (1977)

Mayer, H., Luibrand, G., Goebel, W.: Replication of the mini-R1 plasmid Rsc11 and Rsc11 hybrid plasmids. Molec. gen. Genet. 152, 145-152 (1977)

Meyers, J., Sanchez, D., Elwell, L., Falkow, S.: Simple agarose gel electrophoretic method for the identification and characterization of plasmid deoxyribonucleic acid. J. Bact. 127, $1529-1537$ (1975)

Vosberg, H.P.: Molecular cloning of DNA. An introduction into techniques and problems. Hum. Genet. 40, (1978)

\section{Communicated by F. Kaudewitz}

